\title{
Extension of Clinical/Psychological Approach Using Post-Narratology: Possibility of application on Artificial Intelligence and Robot
}

\author{
Kai Seino \\ Department of Social Rehabilitation of Research Institute, National Rehabilitation Center for Persons with Disabilities, \\ 1, Namiki 4, Tokorozawa City, Saitama Prefecture, 359-8555, Japan
}

E-mail: seino-kai@rehab.go.jp

www.rehab.go.jp/english/index.html

\begin{abstract}
A purpose of this research is to examine the psychological approach from a narrative viewpoint and discuss expanding collaboration with AI and Robot. Methods are a literature review and theoretical examination. As a result, psychological narratology was confirmed to have expanded beyond the so-called narrative therapy. In addition, AI or robot research in the clinical fields have been identified. This will give suggestions to the extension of psychological narratology.
\end{abstract}

Keywords: Narratology, Computational Narratology, Counseling, Clinical Psychology, Disability, Psychiatry

\section{Introduction}

This research examine the potential of combining the narratology as a problem-solving method with techniques such as artificial intelligence (A.I.) or Robot, and the applicability of clinical areas. As a general term, "narrative" is understood as the "act of discussing and being discussed using language (Spoken Language and written language, etc)" (Yamada, 2007). "Narrative" can also be defined more narrowly as in the term "narratology," which refers to the reproduction of real or fictional events and is always accompanied by time constraints (Prince, 2003).

Bruner (1986) suggested that the narrative provides individuals with a method for understanding and thinking about their everyday lives and interactions with others. In recent years, the narrative approach has been utilized in clinical domains such as medicine, nursing, psychology. The narrative may be thought of as an evidence base containing conventional, objective data.
In the clinical domain, the approach is key to any narrative, and is called the narrative approach. For example, representation is a narrative therapy in psychotherapy. However, the conceptualization of a narrative in recent years has not been limited to the narrative approach and is considered to have a wider extent and possibility. One key to understanding the wider possibility of a narrative is the term "narrative generative system," which is advocated by Ogata,. The narrative generative system conceived by Ogata not only considers the structure or form of a story, but also incorporates the process by which the story is constituted and received. In addition, "computational narratology," one of the underlying theories of the narrative generative system, is a concept resulting from the fusion of computational technology and story. Authors have divided narratology into literary narratology and psychological narratology from the viewpoint of a narrative generation system (Seino 2016). A literary

(C) The 2021 International Conference on Artificial Life and Robotics (ICAROB2021), January 21 to 24, 2021 
narratology considers the contents and form of a story, whereas psychological narratology is called a story treatment in the clinical domain and is a narrative approach.

Against the backdrop of Ogata's theory, Seino et al (2016, 2018) proposed a new technique for data mining designed to provide support for persons with disabilities. The technique provides a method for the analysis and generation of a story, through a combination of textmining technology and the viewpoint of literary narratology. The results demonstrated that a theory could be established based on a narrative generative system. However, to investigate the practical implications of the system for the theory and method of a psychological narratology, a discussion of technology (e.g., computer, software, coding) is omitted.

Therefore, the psychological approach is presented in this research from the viewpoint of a narrative, and aims at clarifying the possibility of a psychological narratology. disabilities in order to investigate the possibility of using $\mathrm{AI}$ and robot for narrative research into the clinical field. Method in this research is literature review. Medical treatment and support for any illness that exists in the clinical domain is defined as a psychological approach. In this research, the possibility of extending the psychological approach through collaboration with AI or robot has been examined. Specifically, we review the research and practice of psychology, psychiatry, and a proximity domain in recent years and their use of narrative. Our discussion is broadly focused on the approach and practice relevant not only to narrative therapy but also to a narrative, or to narratology. We will examine the potential of AI and robot using psychological narratology from applications of AI and robotics in research on actual diseases and support for people with disabilities.

\section{A Definition and Theory of a Narrative}

\subsection{Definition of "Narrative"}

A narrative has been defined in multiple ways, and there are also many theoretical positions on the topic (Riessman, 1991). For example, one definition of narrative is that it is an explanation of the experience of a continuous story or people. A narrative may also be communicated using several methods (Clandinin, 2007). Narratology, which is the theory of a narrative, is defined in the narrowest sense in the literary theory of "literary narratology." Moreover, a narrative may be used outside of the field of literature, as in a clinical domain such as psychology, medicine, nursing, and social work that provides services to support persons. The combination of narratology and the use of a narrative in a clinical domain is called "psychological narratology.

\subsection{Literary narratology and "computational narratology" as an application}

The narrowest definition of narratology is regarded as a literary theory, which is the study of the nature, form, and function of narrative (Prince, 2003). Ogata (2010) organized narratology into five categories that establish the theoretical underpinnings of narratology: (1) "The Poetics" of Aristotle; (2) structuralism, which developed based on the ideas of Saussure; (3) the literary art movement of Russian Formalism ; (4) British and American literary theory; and (5) the literary theory of structuralism.

Narrative comprises "story" and "discourse." According to narratology (Prince, 2003), the story is the content of the narrative while the discourse concerns the expressive side. Narratology employs an analysis of both story and discourse. Propp (1968) described the fundamental components of any Russian folktale. In particular, he defined the narratological notions of "function" and characters" "roles." "Function" is a character's act defined from the viewpoint of its significance in the story. Furthermore, Genette (1980) divided discourse into three categories: (1) "tense," which is the temporal relation between discourse and story; (2) "mood," which is the reproduction of the story through the discourse; and (3) "voice," which is the relationship between the narrating and the narrated and the relationship between the narrating and text.

In applied studies of narratology, some researchers analyze and generate stories based on the theories constructed by Propp and Genette (Akimoto \& Ogata, 2013; Ogata, 2011). Regarding these applied studies, Ogata (1999) suggested a study framework called "computational narratology." This research offered a literary study frame that fused an understanding of narratology with the generation of narrative through the use of AI and cognitive science, thereby broadening the concept of computational narratology.

\subsection{Interdisciplinary narrative generative system}

In this section, "interdisciplinary narrative generative system," which is derived from Ogata's narrative generation system, is outlined. Considerable research on story generation has been conducted in the domains of 
cognitive science and AI. Ogata and Kanai (2010) have completed advanced research on the interdisciplinary approach for the narrative generative system, which introduced narratology and literary theory. In addition, Ogata (2011) proposed the concept for the narrative generative system, which continues to be developed at two levels: at a broad level, the narrative generative system constitutes a method for symbolically understanding a human being and society in aggregate; and at a narrow level, a narrative generative system consists of a computer program. Recently, research in the clinical domain, which is based on Ogata's concepts, has been progressing. Specifically, the research is on disease and disability, and the results will be used for clinical support (Aoki et al, 2018; Seino et al, 2016, 2018).

\subsection{The Research Framework for narrative}

Several studies have suggested how to treat a narrative. In a macroscopic position, the framework of a narrative includes all life activities. In a micro position, a narrative (story) expresses the causalities of an event (Riessman, 1993). In addition, the narrative approach is defined as "the method of making the concept of a narrative key and presenting a certain phenomenon" (Noguchi, 2005).

Numerous disciplines study narratives. Ogata (2018) classified the research in the entire discipline with the narrative into three more categories (Table 1).

Table 1. The division between a discipline and narrative

\begin{tabular}{|c|c|c|}
\hline & Classification & The contained discipline \\
\hline 1 & $\begin{array}{l}\text { Symbol level } \\
\text { [Literature, art, and } \\
\text { an entertainments } \\
\text { domain] }\end{array}$ & $\begin{array}{l}\text { Narratology, poetics, rhetoric, } \\
\text { literary criticism, linguistics, } \\
\text { folklore, folktale study, and an old } \\
\text { tale, entertainment research, Noh } \\
\text { play theory, kabuki theory etc., } \\
\text { cultural anthropology and folklore, } \\
\text { philosophy and thought, movie } \\
\text { theory and cinematic review }\end{array}$ \\
\hline 2 & $\begin{array}{l}\text { A brain, a nerve, } \\
\text { and a psychological } \\
\text { level } \\
\text { [Psychiatry and a } \\
\text { psychological } \\
\text { domain] }\end{array}$ & $\begin{array}{l}\text { Psychology, psychiatry and } \\
\text { psychopathology, psychoanalysis, } \\
\text { tale treatment, neuro- } \\
\text { psychoanalysis, brain science (The } \\
\text { author added a postscript.) }\end{array}$ \\
\hline 3 & $\begin{array}{l}\text { Social level [Social } \\
\text { domain] }\end{array}$ & $\begin{array}{l}\text { Sociology, history, business } \\
\text { administration, economics, } \\
\text { jurisprudence, marketing theory, } \\
\text { and advertising theory }\end{array}$ \\
\hline
\end{tabular}

\section{The Narrative in Clinical / Psychological Approach}

In this section, we will examined psychological narratology from the viewpoint of a narrative, and discussed its extension and the possibility of applying it to other areas of research. The conventional clinical domain attaches importance to evidence is objective. The concept of an evidence-based approach originated from evidence-based medicine (EBM) in the 1990s (Guyatt, 1991; Sackett, Richardson, Straus, Rosenberg, \& Haynes, 1997),. Sackett et al. (1997) define EBM as the "the conscientious, explicit, and judicious use of current best evidence in making decisions about the care of the individual patient." Conversely, the idea of "evidencebased" has been reasonably criticized (Gergen, 1994) . Based on the limits of objective facts, social constructivism, which provides the relativist conception of reality, has come to be recognized (Gergen, 1999). Against the backdrop of social constructivism, a trend that allows a reconsideration of EBM from the perspective of the narrative is Narrative Based Medicine (NBM) (Greenhalgh \& Hurwits, 1998). Since the 1990s, the narrative approach has attracted greater attention in interpersonal help domains, such as medical care, nursing, and psychology. The development of epistemology and the methodology that attached importance to narrative is known as the "Narrative Turn." (Denzin \& Lincoln, 2000).

\section{Review of a Psychological Narratology}

The system of a psychological narratology is proposed in this section, which shows that the clinical / psychological approach is extensible through post-narratology. Postnarratology is a narrative generative system that includes story generation by A.I. In order to actuate story generation, a literature review is performed with a clinical/ mental approach considering that the extension to post-narratology is possible. The system then constructs the story through AI and authors argue about the ability of a bridge to be carried out and whether by re-extending the clinical/mental approaches through story generation, a clinical contribution is possible. These approaches are concretely aimed at the approach (research and practice) in clinical domains, such as psychology. A psychological narratology is the theory of the clinical/ psychological approach that is relevant to the

(C) The 2021 International Conference on Artificial Life and Robotics (ICAROB2021), January 21 to 24, 2021 
narrative in the broadest sense that the author has proposed.

\subsubsection{Narrative approach in the counseling}

In the counseling field, a "narrative" has come to be associated with the narrative therapy since the 1980s. In a narrow sense, psychological narratology is narrative therapy in psychotherapy and family therapy. Narrative therapy was advocated by White and Epston (1990) and it developed through the context of family therapy in the 1980s. White and Epston (1990) applied a classification of Foucault (1980) to narrative therapy, aiming to excavate the new "alternative story" from the "dominant story" that restricts life. This excavation is conducted by "externalizing" and seeking a "unique resolution" for the problem. In addition, Spence (1983) described the occurrence in which a narrator is in treatment, and a hearer hears the talk of a narrator as a tale. In analytic psychology, the role of a "tale," like the myth, is touched upon by Kawai (2001), who presupposes that the process of psychotherapy is a tale. In addition, in Gestalt therapy, Polster (1987) presupposed that the recovery of harmony of the heart requires a dialog, and proposed the method of making achieving this harmony is by having a real person sit on an "empty chair" that is assumed to be there and engage in a dialog.

\subsubsection{Consideration of a proposal}

Narrative therapy creates a narrative that provides the client with a tool for problem solving. A typical narrative approach heads toward the solution to a question as the client completes a tale. We propose the following possibility from the viewpoint of post narratology: what is treated is the discovery or description of a "dominant story" and an "alternative story," and the technique of externalization. There are two implications of this suggestion. First, the "dominant story" and "alternative story" may be identified in order to construct the theory of a narrative generative system. Second, computational technology may be able to realize two stories.

\subsection{Self-help group}

\subsubsection{The group for mutual aid}

A self-help group is practiced among those who suffer from the same illness and offers support through peer relations. For example, self-help groups may be formed for individuals addicted to alcohol, drugs/psychotropic substances, or gambling, or who are dealing with the same life obstacle or chronic malady. In recent years, self-help group have come to be viewed as a form of a narrative approach (Noguchi 2005). "Alcoholics Anonymous (AA)" was the first self-help group, which was developed in the United States in 1935, and is for recovery from alcohol addiction. AA was effective for treating alcohol addiction, and over time, many other groups adopted the method used by AA to deal not only with addiction or dependence but also for other problems. The typical definition of a self-help group is that of Kats $\&$ E. I. Bender (1976), who defined a self-help group as a small group of companions (peers) who provide mutual aid for the achievement of a specific purpose. AA meetings are regularly scheduled and the members who gather at each meeting talk in turn about various topics. The talk may be of experiences from one's past or the utterance of a single word may constitute a speaking turn (Noguchi 1995). The self-group does not have a technical definition (Ito, 2000).

\subsubsection{Consideration of a proposal}

The first-line specialty of support of a self-help group is "experiential knowledge." Experiential knowledge is the knowledge based on a member's experience, and serves as a source of support for a self-help group. The knowledge of members is more practical and more comprehensive than the knowledge of professionals (Borkman 1976). Each member's “experiential knowledge" is discussed and the collective knowledge if the group is accumulated and utilized as one tale knowledge from a group. We can interpret sharing of knowledge as the process of making one big narrative from two or more members' narratives. The process may be adopted into theory as a narrative generative system and may be realized as a system. For example, studies have proposed collect many texts that were spoken and generating the tale based on some typical elements. In addition, Ito (2000) examined a self-help group from the perspective of an individual tale. The results of the study indicated that the tale should have been regarded as an object with the effect of showing not the collective knowledge system of a group, but of a participant's self. To determine the degree of change for each participant, it was presupposed that it was important to determine the standard by which a participant made a tale "the good talk." In other words, it was important for a tale or suggestion to achieve a set basis for valuation. An 
evaluation of the tale could be conducted based on how the group absorbed the tale and how it affected the production and consumption of future tales.

\subsection{Open Dialogue}

\subsubsection{Philosophy of discussing}

In recent years, Open Dialogue (OD) is another psychological approach that has attracted attention in Japanese psychiatry. OD started in Finland in the 1980s and is a method of therapeutic intervention for an acuteterm mental disease. In OD, two or more staff conduct a crisis intervention within 24 hours of a request. Patients and families practice OD every day by sitting in a circle and performing "OD." OD seldom uses a drug but makes a patient's critical situation cease (Saio 2014). All matters are discussed and determined as a characteristic portion of OD at the members' meeting place. In addition, an expert team discusses a patient and a family (exchange) in their presence, as they reflect on what is being shared with them. Olson, Seikkula, and Ziedonis (2014) summarized the following key OD items:

\subsubsection{Consideration of a proposal}

OD is considered to be a narrative approach given that a conversation called a dialog becomes a key medical treatment. OD contains narrative therapy and a common feature of OD is that it has an ideological background. In addition, it is also a common feature with narrative therapy to use reflecting. The 12 elements of OD consider tale generation and its effect, and the process is thought provoking. A dialogue is performed by two or more members of various positions. In addition, open-ended questions are used as an interlocutory trigger. OD may be able to be realized as an automatic dialogue system or a narrative system by speech recognition. By pulling out two or more viewpoints and observing relationships, an automatic dialogue system may be able to return utilize an extraction method to return an element as the narrative is being generated.

\subsection{Tohjisha-Kenkyu (Self-directed studies)}

\subsubsection{Empowerment approach by oneself and a companion}

In recent years, the "Tohjisha-Kenkyu" approach that originated in Japan has attracted international attention. Tohjisha-Kenkyu may be introduced as an open dialog in Japan (Saito 2016) and is an approach commonly used with patients with schizophrenia. In recent years, it has also been developed as a treatment for persons with developmental disabilities. Tohjisha-Kenkyu is an empowerment approach, and it happened among the activity and liveing of the person with disabilities (Mukaiyachi, 2013).

\subsubsection{Consideration of a proposal}

Tohjisha-Kenkyu provides suggestions for examining a narrative generative system and how to connect narrative generation for problem solving. In Tohjisha-Kenkyu, it is assumed that the party concerned will themselves become a hero of difficulties. In addition, TohjishaKenkyu allows the narrative to pass and has suggested that it is a narrative approach tied to the problem solving of the party concerned. In addition, Noguchi (2005) reported that Tohjisha-Kenkyu is "a community of narration" that makes it "the community of the tale." Many audiences are in a "narrative community," and new narration becomes more certain with an existing audience. A narrative community is the space wherein new narration is shared and established. In addition, the aspects of changing attitudes, and how to identify and position attitudes Tohjisha-Kenkyuare are also common in narrative therapy. Moreover, the conceptualization of one's own experience and that of a friend is similar to the notion of "experiential knowledge" in a self-help group. In addition, when considering tale generation, an improvisatorial, unique understanding or an idea is important and shows how to utilize the result, which creates a "relation" as a "behavior" in a scene received by the narrative generative system.

\section{Psychological Approach for Application of A.I.}

In this section, two studies of the clinical/ psychological approach and the possibility of narrative generation by A.I. are introduced. 


\subsection{Narrative generation for employment support of persons with disabilities}

In this section, the authors' research is introduced, in which we extracted text elements and employed a system of story generation using A.I. Specifically, we analyzed a disabled person's free descriptive answer to an interview question using the method of "informatics tale analysis" to extract the elements of the story. This method combines the technology of text mining, and some theories of a literary narratology. Text mining involves the quantitative analysis of text data based on natural language processing or data mining. After we extracted the element of the story from the individual's text response, the system proposed creating a collectivestory. An example of the narrative is shown below. Please note that to protect respondents' privacy, some answers are altered, but the basic meanings remain unchanged. In the authors' study, both the wider and narrow senses of narrative were used depending on the particular contexts of the analysis.

[Concerning work description] In response to the question: "Describe your job in detail."

Example 1: Since my legs were injured, I have been assigned paperwork. I am now engaged in computer work. (Physical disability)

[Concerning care and support at the workplace] In response to the question: "Specify the care and support provided in your workplace as a means of assisting your career."

Example 2: At my workplace, employees often get acquainted with coworkers at informal meetings, such as drinks parties. I did not attend these parties because of my disease, so I had no opportunity to get to know them. The other day, I took the opportunity of participating in one, and it worked much more effectively than I had expected. (Mental disorder)

Example 3: I first wanted to work without mentioning my disease. The other day, a relative of a person who had supported me asked me to work in their office. When I began working there, I soon found that this relative did not care about my condition, so it was a disastrous year. From this experience, I realized that I should conceal my disease because people consider me to be inferior to healthy people. (Intractable disease)

The authors' study analyzed the descriptive texts that reflected the personal stories of persons with disabilities, and clarified social stories of disability based on the results of multivariate analysis involving text mining. This is an example from our research entitled "Employment Support and Story Generation for Students with Developmental Disabilities." The results indicated that story generation tends to materialize through the combining of existing elements with those from previous research (Seino, Enomoto, \& Miyazawa, 2018). The figure below shows a story generative system.

The analysis of job descriptions analysis results were used to create the image. For cases in which this system was created, it was important to consider how elements were combined. The probability of a story being generated is attained by calculating the probability that it may happen and the strength of the relationship between the text elements. In addition, in order to utilize the result of the support generation simulation, it is important to understand what kind of elements have been collected. For example, the elements of support needs may be collected based on responses to a specific problem, and it may be possible to examine what kind of problem and support needs occur at what time, thus enabling the preparation of appropriate support.

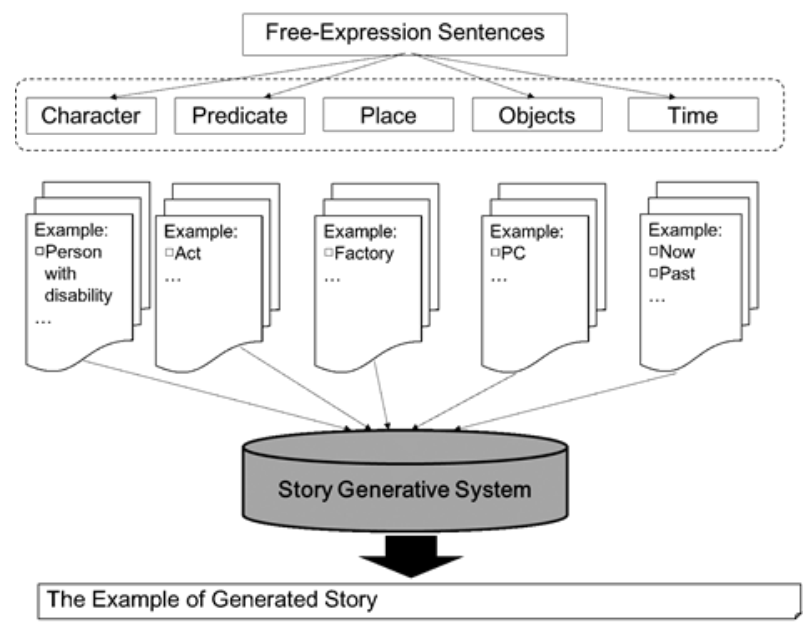

Fig. 1. The image of the story generative system

\subsection{Narrative generation for paper creation support of a student with a developmental disease tendency}

Joint research by Ogata and Aoki et al. (Aoki, et al. 2018) proposed students' paper creation support and narrative generative system based on the cognitive tendencies and action patterns of individuals with autism spectrum 
disorders. Aoki et al (2018) suggested that a paper creation might address the problem of a student with autism spectrum disorder. they explained why the problem occurs based on the cognitive tendencies and the action patterns of people with autism spectrum disorder, who may be sensitive to "a surprise and a gap" in the "discontinuous nature" of a story. Therefore, a story (paper creation), after making it continuous, stops the reaction of a student with autism spectrum disorder. The evaluation mechanism was set up and support was proposed for advancing a story by issuing directions on a macro and a micro level.

\section{AI and ROBOT for interpersonal support and clinical practice}

In this section, we review some of the practical applications of $\mathrm{AI}$ and robot in assisting patients and people with disabilities as a reference for considering AI and robotics applications in narratology.

\subsection{AI applications in psychiatric research}

Ikeda (2019) reviewed the use of AI in the psychiatric field.

According to this study, 393 articles were extracted from the article search database Pubmed using keywords related to psychiatry and AI. In the 382 abstracts obtained, the most frequently occurring psychiatric diagnoses were depression, schizophrenia, and Alzheimer's_disease. In addition, the research objectives of these articles were mainly the following four. (1) to improve the accuracy of medical treatment (e.g., diagnostic support, prediction of treatment effects and side effects, etc.), (2) to elucidate the etiology and pathogenesis of diseases (e.g., genome analysis, image analysis, etc.), (3) to develop new treatment methods (e.g., drugs and medical devices), and (4) to reconstruct diagnostic concepts and systems. The AI-related terms in those papers are, in descending order of frequency, support_vector_machine, random_forest, logistic_regression, deep_learning, natural_language_processing, decision_tree, convolution decision_tree, convolutional_neural_network, and naive_bayes.

The following is an overview of the specific studies.

\subsection{Use of machine learning in AI}

AI is being used in research to predict disease and identify contributing factors.

Rahman et al (2020) developed a method for predicting autism in newborns by machine learning the parents' age, socioeconomic status, medication, etc. from their medical records.

This algorithm clarifies, autism and the use of substances such as caffeine and certain antidepressants by parents are relevant. The results may also help to identify factors that may induce autism.

AI has also been used in research to differentiate between diseases and disease subtypes. Stevens et al (2019) analyzed behavioral data in autism and found two comprehensive behavioral profiles. Each profile had its own subgroups based on the severity of different traits.

Chand et al (2020) used machine learning to analyze brain scans of schizophrenia and clinical information such as age of onset and medication use. As a result, they identified two subgroups of schizophrenia based on different patterns of brain structure. One of the subtypes showed brain volume increasing almost normally in two regions, rejecting previous ideas that schizophrenia is associated with reduced brain volume.

Koike and his research group developed a machine learner that determines schizophrenia and developmental disorders through image analysis by machine learning of magnetic resonance imaging (MRI) brain structure images (Yassin et al, 2020).

Thus, machine learning research is expected to be applied to differential diagnosis and treatment prediction in clinical practice. It may also be useful for discovering subtypes of the same disease and understanding the reasons for differences in nature and severity.

\subsection{Robots for Supporting Children with Autism Spectrum Disorder (ASD)}

Hirokawa (2014a, 2014b) et al. have proposed a robot intervention activity for children with autism spectrum disorder (ASD), a developmental disability, to improve their social skills and promote their communication abilities. They have developed a robot manipulation interface that can be used by supporters for this purpose, as well as a method for quantitatively measuring face-to- 
face behavior and facial expression during intervention activities, and have verified its effectiveness.

Jain et al (2020) developed a machine learning algorithm that automatically tells a robot when to encourage Autism Spectrum Disorder (ASD), as a therapeutic intervention. The reason for the use of robots in these proposals is that humanoid robots, with mechanical features that are highly compatible with ASD children and physical and social characteristics similar to those of humans, are expected to play an important role in interventions for ASD children.

\section{Discussion}

\subsection{Extension and possibility of a psychological narratology}

In this paper, the psychological narratology was divided into some items and reviewed. The author showed that the narrative approach in clinical domain, defined as psychological narratology, went beyond the narrative therapy in psychotherapy and was expanded to various experiments and research. Moreover, is thought that three features are among the psychological narratologies reviewed in this paper. As the first, many practice is not simple technology and method but stance, and a way of thinking. Since it has narrative approach against the background of social constructionism, fixation is avoided and relativized. As the second, the narrative can point out being made communally. The third point is all the tales are built through a dialog. They were not monologues and were constructed through colloquial expressions.

Based on these points, the narrative generative system is considered in both a narrow sense and a broad sense. The following possibilities exist regarding the automatic tale generation machine realized as a narrative generative system in a narrow sense, i.e., a computer program etc. (1) It is the construction of a fluid system. For example, a random element is taken in accepted. This system carries out narrative generation by combining elements. (2)Two or more persons are the systems that generate a tale communally. (3) It is a system of the tale generation through simple dialogue but not an input.

In addition, the following is mentioned as a suggestion for the practice of this research. A psychological narratology is not merely a methodology but is also the mechanism for converting of a relative sense of values. It is given significance with conversion (or improvement) of the worth of the tale of the party concerned and the party concerned. The following specific suggestions are based on such a system. (1) Consider the community itself which generates a tale and utilizes it to be a system and as well as its construction and practical use. (2) The idea of a system and the realization that this idea places more value on the process rather than the contents of tale generation. (3) Get participation and collaboration of the concerned parties towards realization and practical use of a system.

\subsection{Potential Applications of Psychological Narratology to AI or Robot}

Research had been accumulated on the use of AI and robot for clinical support and it was confirmed that algorithms had already been developed or started to be implemented on robots. In addition, the previous studies had the following four main objectives (Ikeda, 2019). (1) Improvement of medical treatment system, (2)

Elucidation of etiology and pathogenesis, (3) Development of new treatment methods, (4) Reconstruction of diagnostic concepts and systems Firstly, by machine learning of existing data, the use of AI in clinical support has enabled to predict and identify diseases, discover subtypes, and identify factors in the development of diseases (Stevens et al, 2019; Rahman et al, 2020; Chand et al, 2020; Yassin et al, 2020).

If this method is applied to psychological narratology, applications to detect subtype, and to predict and identify tasks are considered throughout machine learning of speech, dialogue, and written text data.

Secondly, the use of robots for clinical support had been studied to improve the convenience and effectiveness of robots for supporting children with autism spectrum disorder (Horikawa, 2014, 2014b; Jain et al, 2020). If the application to psychological narratology is considered from this point, incorporating narrative elements into robot for autism spectrum disorders is possible. Also, it may be necessary to examine the effectiveness of robot support for non-autism spectrum disorders.

\section{Conclusion}

This research defines the narrative approach of a clinical domain as a psychological narratology, and examines its extension and possibility for application on AI or robot. As a result of the review, psychological narratology was confirmed to have widely expanded beyond the so-called

(C) The 2021 International Conference on Artificial Life and Robotics (ICAROB2021), January 21 to 24, 2021 
narrative therapy of psychotherapy and family therapy. In addition, suggestions from these practices are thoughtprovoking and also utilize expansion, realization, and the system of the narrative generative system in a narrow sense and a broad sense for actual problem solving. In addition, AI or robot research in the clinical domain has been identified. This gives suggestions to the extension of psychological narratology. It is meaningful to consider the practice of a clinical domain from the viewpoint of a narrative, as well as in respect to clinical reduction. We expect that expansion of new discovery and practice will be performed because a supporter, and a researcher in connection with a theme, and the researcher of related domains, such as A.I., computing science, cognitive science, will argue and collaborate in the future.

\section{References}

1. Y. Yamada, Shitsutekishinrigaku no houhou: Katari o kiku [Method of qualitative psychology: Listening to narrative]. Shinyousha, 2007.

2. G. Prince, A dictionary of narratology (Revised ed.). University of Nebraska Press, 2003.

3. J. Bruner, Actual minds, possible worlds, Harvard University Press, 1986.

4. K. Seino, K, Y. Haruna and S. Ishizaki, Employment status and support needs of persons with disabilities in Japan: An analysis of narrative using narratology and text mining on a national survey. in T. Ogata, and T. Akimoto (eds.), Computational and cognitive approaches to narratology (pp .245-275). Information Science Reference, IGI Global, 2016.

5. K. Seino, Y. Enomoto and S. Miyazawa, Narrative analysis of employment support for students with developmental disabilities: Using an objective analysis of free-expression answers. In T. Ogata and S. Asakawa (eds.), Content generation through narrative communication and simulation (pp. 341-357). Information Science Reference, IGI Global, 2018.

6. C. D. Riessman, Beyond reductionism: Narrative genres in divorce accounts, in Journal of Narrative and Life History, 1(1), 1991, pp.41-68.

7. D. Clandinin, D. (ed.), Handbook of narrative inquiry: Mapping a methodology. Sage Publications, 2007.

8. T. Ogata (2010). "Monogatari seisei sisutemu" no haikei oyobi monogatari to bungaku no aida [Backgrounds of the "narrative generation system" and "relations between narrative and literature"]. In T. Ogata \& A. Kanai, Monogatariron no jouhougaku josetsu: monogatari seisei no shisou to gijutsu wo megutte [An introduction to the informatics of narratology: about the thought and technologies of narrative generation] (pp. 186-258) Tokyo, Japan: Gakubunsha.

9. V. Y. Propp, Morphology of the folktale (L. Scott, Trans.) University of Texas Press, 1968 (Original work published 1928).

10. G. Genette, Narrative discourse: An essay in method (J. E. Lewin, Trans.). Cornell University Press, 1980. (Original work published 1972).

11. T. Akimoto, T and T. Ogata, Towards a discourse mechanism in narrative generation system: Proposal of a system introducing narrative discourse theory and reception theory. Cognitive Studies, 20(4), 2013, pp.396420.

12. T. Ogata, Narrative generation system as the practice of "informatics of narratology." Journal of Japan Society for Fuzzy Theory and Intelligent Informatics, 23(5), 2011, pp.676-685.

13. T. Ogata, Proposal of computational narratology. In Proceedings of IPSJ SIG Computers and the Humanities (pp. 53-60), 1999.

14. S. Aoki, T. Ogata and J. Ono, Narrative generation related to cognitive patterns seen in ASD -From the perspective of "Surprise"-, In Proceedings of the 35th Annual Meeting of the Japanese Cognitive Science Society (pp. 652-660). (2018).

15. C. K. Riessman, Narrative analysis. Newbury Park, CA: Sage, 1993.

16. Y. Noguchi (ed.), Naratibu no rinshoshakaigaku [Clinical sociology of narrative]. Keiso shobo, 2005.

17. T. Ogata, Narratology of Narrative Generation or PostNarratology, in Cognitive Studies, 25(2), 2018, pp.200217.

18. G. H. Guyatt, Evidence-based medicine. American College of Physicians Journal Club, 1991. 114, A-16.

19. D. L. Sackett, W. S. Richardson, W. Rosenberg and R. B. Haynes, Evidence-based medicine: How to practice and teach EBM. New York, NY: Churchill Livingstone, 1997.

20. K. J. Gergen, Toward transformation in social knowledge. Sage Publications, 1994.

21. K. J. Gergen, An invitation to social construction. Sage Publications, 1999.

22. T. Greenhalgh and B. Hurwitz (eds.), Narrative based medicine, BMJ Books, 1998.

23. N. K. Denzin and Y. S. Lincoln (eds.). Handbook of qualitative research, Sage Publications, 2000.

24. M. White and D. Epston, Narrative means to therapeutic ends. New York: Norton. in Transformative Learning Conference, Oct. 1990, pp. 23-25, 2003 184/492

25. M. Foucault, Power/knowledge. (C. Gordon, L. Marshall, J. Mepham and K. Soper, Trans.). Pantheon Books ,1980. (Original work published 1972, 1975, 1976, 1977).

26. C. D. Spence , Narrative persuasion, in Psychoanalysis and Contemporary Thought, 6, 1983, pp. 457-468. 
27. H. Kawai, Shinriryoho niokeru Monogatari no Igi [Significance of the "narrative" in psychotherapy], in Japanese Journal of Psychotherapy, 27, 2001, pp. 3-7.

28. E. Polster, Every person's life is worth a novel. W. E. Norton \& Company Inc, 1987.

29. A. H. Katz and E. I. Bender (eds.), The Strength in Us: Self-Help Groups in the Modern World. New York: New Viewpoints, 1976).

30. T. Borkman, Experiential knowledge: A new concept for the analysis of self-help groups. in Social Service Review, 50 (3), 1976, pp.445-456.

31. T. Ito, Serufu herupu gurupu to kojin no monogatari [Selfhelp groups and personal stories]. in Japanese Sociological Review, 51(1), 200, pp. 88-103.

32. T. Saio, Open dialogue approach to acute psychosis: Is its effectiveness well-established? in Clinical Evaluation, 42 (2) , 2014, pp. 531-537.

33. I. Mukaiyachi, Tojisha-kenkyu toha: Tojisha-kenkyu no rinen to kousei [What is a Tojisha-Kenkyu? The concept and structure of a Tojisha-Kenkyu]. Tojisya-Kenkyu network (https://toukennet.jp/?page_id=56), 2013.

34. S. Ikeda, Current Trends, Issues and Potentiality of AI Technology in Psychiatry. in The 33rd Annual Conference of the Japanese Society for Artificial Intelligence, 2N5-J13-03, 2019, pp. 1-4.

35. R. Rahman, A. Kodesh, S. Z. Levine, S. Sandin, A. Reichenberg and A. Schlessinger, Identification of newborns at risk for autism using electronic medical records and machine learning, in Eur Psychiatry, 63(1), 2020, e22.

36. E. Stevens, D. R. Dixon, M. N. Novack, D. Granpeesheh, T. Smith and E. Linstead, Identification and analysis of behavioral phenotypes in autism spectrum disorder via unsupervised machine learning. in Int J Med Inform, 129, 2019, pp. 29-36

37. G. B. Chand, D. B. Dwyer, G. Erus, A. Sotiras, E. Varol and D. Srinivasan,et al. , Two distinct neuroanatomical subtypes of schizophrenia revealed using machine learning. in Brain, 143(3), 2020, pp. 1027-1038.

38. W. Yassin, H. Nakatani, Y.Zhu, M.Kojima and Owada K., et al., achine learning classification using neuroimaging data in schizophrenia, autism, in Translational Psychiatry. 10(1), 2020, pp.278.

39. M. Hirokawa, A. Funahashi, and K. Suzuki, A Doll-type Interface for Real-Time Humanoid Teleoperation in Robot-Assisted Activity: A Case Study, in Proc. ACM/IEEE Intl. Conf. on Human-Robot Interaction, 2014, pp.174-175.

M. Hirokawa, A. Funahashi, Y. Itoh and K. Suzuki, Design of affective robot-assisted activity for children with autism spectrum disorders, in Proc. of The 23rd IEEE International Symposium on Robot and Human Interactive Communication, 2014, pp. 365--370.

40. S. Jain, B.Thiagarajan, A.Shi, C. Clabaughand and M.J. Matarić, Modeling engagement in long-term, in-home socially assistive robot interventions for children with autism spectrum disorders, in Sci. Robot, 5(39), 2020, eaaz3791. 